Article

\title{
Simultaneous Analysis of Iridoid Glycosides and Anthraquinones in Morinda officinalis Using UPLC-QqQ-MS/MS and UPLC-Q/TOF-MS ${ }^{\mathrm{E}}$
}

\author{
Xiangsheng Zhao ${ }^{1}$, Jianhe Wei ${ }^{1,2}$ and Meihua Yang ${ }^{1,2, *}$ \\ 1 Hainan Branch Institute of Medicinal Plant Development, Chinese Academy of Medical Sciences \& Peking \\ Union Medical College, Haikou 571100, China; xiangshengzhao@hotmail.com (X.Z.); wjianh@263.net (J.W.) \\ 2 Institute of Medicinal Plant Development, Chinese Academy of Medical Sciences \& Peking Union Medical \\ College, Beijing 100193, China \\ * Correspondence: yangmeihua15@hotmail.com or mhyang@implad.ac.cn; Tel.: +86-10-5783-3277
}

Academic Editors: Giuseppina Paola Parpinello and Derek J. McPhee

Received: 2 April 2018; Accepted: 2 May 2018; Published: 3 May 2018

\begin{abstract}
Morinda officinalis is an important herbal medicine and functional food, and its main constituents include anthraquinone and iridoid glycosides. Quantification of the main compounds is a necessary step to understand the quality and therapeutic properties of $M$. officinalis, but this has not yet been performed based on liquid chromatography/tandem mass spectrometry (LC-MS/MS). Analytes were extracted from M. officinalis by reflux method. Ultrahigh-performance liquid chromatography coupled with a triple quadrupole mass spectrometry (UPLC-QqQ-MS) using multiple reaction monitoring (MRM) mode was applied for quantification. Fragmentation pathways of deacetyl asperulosidic acid and rubiadin were investigated based on UPLC with quadrupole time-of-flight tandem mass spectrometry (Q/TOF-MS) in the $\mathrm{MS}^{\mathrm{E}}$ centroid mode. The method showed a good linearity over a wide concentration range $\left(R^{2} \geq 0.9930\right)$. The limits of quantification of six compounds ranged from 2.6 to $27.57 \mathrm{ng} / \mathrm{mL}$. The intra- and inter-day precisions of the investigated components exhibited an RSD within $4.5 \%$ with mean recovery rates of $95.32-99.86 \%$. Contents of selected compounds in $M$. officinalis varied significantly depending on region. The fragmentation pathway of deacetyl asperulosidic and rubiadin was proposed. A selective and sensitive method was developed for determining six target compounds in M. officinalis by UPLC-MS/MS. Furthermore, the proposed method will be helpful for quality control and identification main compounds of $M$. officinalis.
\end{abstract}

Keywords: Morinda officinalis; iridoid glycosides; anthraquinones; fragmentation behaviors; LC-MS/MS

\section{Introduction}

Morinda officinalis F.C. How (Rubiaceae) mainly grows in tropical and subtropical regions, such as Guangdong, Hainan, Guangxi, and Fujian provinces of China [1]. Its roots-an important traditional Chinese medicine (TCM) and functional food-have been widely used for the treatment of sexual impotence, spermatorrhea, irregular menstruation, and female infertility for more than 2000 years [2,3]. To date, pharmacological studies have revealed that $M$. officinalis exhibits antiosteoporosis, antifatigue, antioxidative, antidepressant, and hypoglycemic activities [4-7]. Iridoid glycosides, anthraquinones, polysaccharides, and oligosaccharides are the main bioactive constituents of M. officinalis [8,9]. In Chinese Pharmacopoeia (2015 edition), nystose assay using high-performance liquid chromatography (HPLC) and thin layer chromatography (TLC) identification was performed for quality control of M. officinalis [3]. As is known, herbal medicines exert their curative effects through multiple components on multiple targets [10]. Despite the beneficial effects and biological 
activities of anthraquinones and iridoids [4,11,12], few reports on their simultaneous identification and quantitation are available.

Currently, several analytical methods based on HPLC coupled to ultraviolet detection (UV) [13-17] or mass spectrometry (MS) (Li et al., 2016) have been reported for the determination of anthraquinones or iridoid glycosides in M. officinalis. However, these methods suffered from low resolution or long run-time, with few of these investigations being conducted for the simultaneous determination of multicomponents in this herbal medicine [18]. Therefore, development of a reliable approach to quantify multiple bioactive constituents for the comprehensive quality control of $M$. officinalis is of great importance. Ultrahigh-performance liquid chromatography-triple quadrupole mass spectrometry (UPLC-QqQ-MS/MS) method in multiple reaction monitoring (MRM) mode has drawn much attention for the analysis of active compounds in herbal medicines due to its high speed, improved sensitivity and specificity, and superior accuracy $[19,20]$. Furthermore, it is a powerful approach to solve the problems mentioned above, with added benefits of short run-times and less solvent consumption. In addition, due to its high resolution, sensitivity, and accuracy, UPLC-Q/TOF-MS/MS has become a dominant tool to analyze the chemical components of TCM. Moreover, it can also provide isotopic abundances and the elemental composition of fragment ions, which are greatly valuable to the structural inference of unknown ingredients [21,22].

Hence, in this work, we established a UPLC-QqQ-MS/MS method in the MRM mode for determining six active components (monotropein, deacetyl asperulosidic acid, asperulosidic acid, asperuloside, rubiadin-1-methyl ether, and rubiadin, Figure 1) in M. officinalis collected from different origins in China. Then, UPLC-Q/TOF-MS/MS was employed to further confirm the anthraquinones and iridoid glycosides in the methanolic extract of M. officinalis. The fragmentation behavior of iridoid glycosides and anthraquinones was explored in negative mode. This study served as the first example of comprehensive quality control and knowledge expansion for the quantification and identification of multiple compounds in M. officinalis.<smiles>O=C(O)C1=COC(OC2O[C@H](CO)[C@@H](O)[C@H](O)[C@H]2O)C2C1C=CC2(O)CO</smiles>

monotropein<smiles>CC(=O)OCC1=CC(O)C2C(C(=O)O)=CO[C@H](O[C@@H]3O[C@H](CO)[C@@H](O)[C@H](O)[C@H]3O)[C@H]12</smiles>

asperulosidic acid<smiles>O=C(O)C1=COC(OC2O[C@H](CO)[C@@H](O)[C@H](O)C2O)C2C(CO)=CC(O)C12</smiles>

deacetyl asperulosidic acid<smiles>CC(=O)OCC1=CC2OC(=O)C3=COC(O[C@@H]4O[C@H](CO)[C@@H](O)[C@H](O)[C@H]4O)[C@H]1C32</smiles>

asperuloside<smiles>Cc1c(O)cc2c(c1O)C(=O)c1ccccc1C2=O</smiles>

rubiadin<smiles>COc1c(C)c(O)cc2c1C(=O)c1ccccc1C2=O</smiles>

rubiadin-1-methyl ether<smiles>COc1cc(-c2cc(=O)c3c(O)c(OC)c(O)cc3o2)ccc1O</smiles>

jaceosidin

Figure 1. Chemical structures of the six compounds and jaceosidin (internal standard, IS). 


\section{Results and Discussion}

\subsection{Optimization of UPLC-QqQ-MS/MS Conditions}

To achieve good resolution and short analysis time of the selected compounds, several UPLC analytical parameters were optimized, including mobile phase, column type, and temperature, and flow rate of mobile phase. Taking the polarity of anthraquinone and iridoid glycosides into consideration, an Xbridge BEH $\mathrm{C}_{18}$ column $(150 \mathrm{~mm} \times 4.6 \mathrm{~mm}, 5 \mu \mathrm{m}$; Waters Corp., Milford, MA, USA) was selected for their separation, which provided smoother baseline and superior resolution of the analytes as compared to other chromatographic columns. Then, several organic solvents and aqueous buffer were investigated to minimize peak width and maximize signal intensity. Acetonitrile with stronger elution capability satisfies the requirement of faster elution of analytes and shorter analysis time. Formic acid was selected as the aqueous solvent additive at the concentration of $0.3 \%$ over acetic acid. Therefore, the optimal mobile phase, consisting of acetonitrile and water $(0.3 \%$ formic acid), was finally employed. Furthermore, the effects of column temperature and flow rate were also investigated, and a column temperature of $40{ }^{\circ} \mathrm{C}$ and a flow rate of $0.4 \mathrm{~mL} / \mathrm{min}$ were found to produce the optimal results (Figure 2).

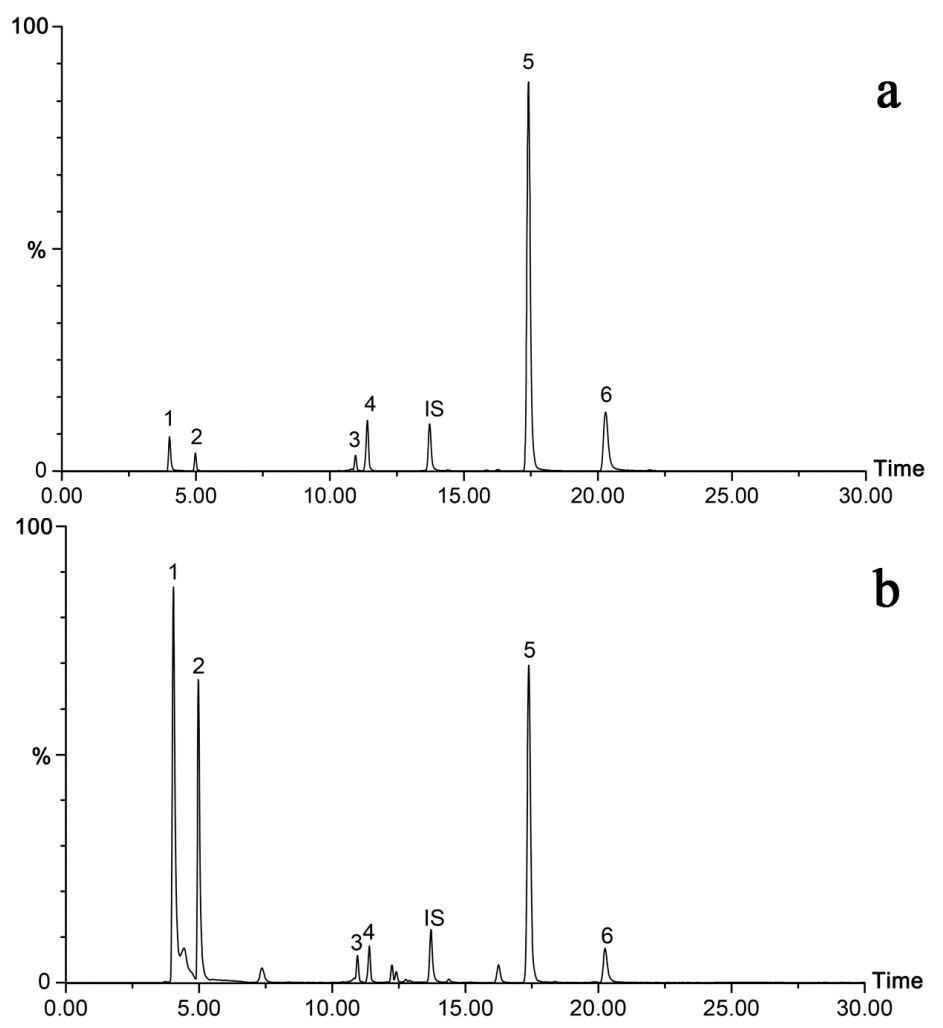

Figure 2. UPLC-MS/MS multiple reaction mode (MRM) chromatograms of (a) mixed standards and (b) M. officinalis samples. 1, monotropein; 2, deacetyl asperulosidic acid; 3, asperulosidic acid; 4, asperuloside; 5, rubiadin-1-methyl ether; 6, rubiadin; IS, jaceosidin. Analyte numbering in the test is the same as in this figure.

For optimizing the MS/MS parameters, individual analyte solutions $(1.0 \mu \mathrm{g} / \mathrm{mL})$ were directly infused into the mass spectrometer under the positive and negative ionization scan mode. Under the selected electrospray ionization (ESI) condition, all six analytes and IS showed higher sensitivity in the negative ionization mode. Consequently, deprotonated molecules $[\mathrm{M}-\mathrm{H}]^{-}$were selected as precursor ions. To obtain the maximum response of precursor and product ions, the parameters for fragment voltage and collision energy were further optimized. Other parameters-such as ESI source, 
desolvation temperature, and flow rate of the desolvation gas and cone gas-were also optimized. All the MRM transitions and parameters applied in the study are shown in Table 1.

Table 1. MS parameters of the target analytes and jaceosidin.

\begin{tabular}{cccccc}
\hline Analytes & $\begin{array}{c}\text { Retention } \\
\text { Time }(\mathbf{m i n})\end{array}$ & $\begin{array}{c}\text { Parent } \\
(\mathbf{m} / \mathbf{z})\end{array}$ & $\begin{array}{c}\text { Daughter } \\
(\mathbf{m} / \mathbf{z}) \mathbf{( Q / I )})^{\mathbf{a}}\end{array}$ & $\begin{array}{c}\text { Cone } \\
\text { Voltage }(\mathbf{V})\end{array}$ & $\begin{array}{c}\text { Collision } \\
\text { Energy (eV) }\end{array}$ \\
\hline Monotropein & 4.03 & 388.98 & $146.95 / 190.95$ & 47 & $20 / 25$ \\
Deacetyl asperulosidic acid & 4.98 & 389.12 & $118.93 / 164.95$ & 45 & $24 / 21$ \\
Asperulosidic acid & 10.96 & 431.05 & $251.03 / 165.01$ & 48 & $22 / 20$ \\
Asperuloside & 11.41 & 413.03 & $146.95 / 190.94$ & 51 & $18 / 23$ \\
Rubiadin-1-methyl ether & 17.42 & 267.02 & $223.99 / 251.95$ & 50 & $25 / 25$ \\
Rubiadin & 20.29 & 252.97 & $224.01 / 209.96$ & 50 & $30 / 26$ \\
Jaceosidin (IS) & 13.73 & 328.98 & $313.95 / 298.96$ & 50 & $22 / 22$ \\
\hline
\end{tabular}

${ }^{a} \mathrm{Q}:$ transitions for quantification; I: transitions for identification.

\subsection{Optimization of Sample Preparation}

Sample preparation is a critical step for developing an accurate and reliable LC-MS/MS quantitative analysis of multiple components. To optimize the preparation of sample solution, the extraction method (reflux and ultrasonication), extraction time (30, 45, 60, and $75 \mathrm{~min}$ ), solvent volume $(15,25$, and $35 \mathrm{~mL}$ ), and extraction repetition (1 and 2 times) were investigated using the sample S13 collected from Hainan province of China. Regarding the extraction method, heat refluxing extraction showed better extraction yield, especially for rubiadin-1-methyl ether and rubiadin (Figure 3). Hence, refluxing extraction was selected as the extraction approach in this study. For the volume of extraction solvent, $25 \mathrm{~mL}$ of methanol was found to be more effective for the samples, as it provided the highest yields of all six ingredients. According to the peak area of analytes, $60 \mathrm{~min}$ was selected as the extraction time. Furthermore, extraction repetition (1 and 2 times) was compared and the results indicated that repetition did not show a significant impact on extraction efficiency. As a result, the optimal sample preparation method was summarized as the extraction of $1.0 \mathrm{~g}$ sample with $25 \mathrm{~mL}$ of methanol by refluxing for $60 \mathrm{~min}$.
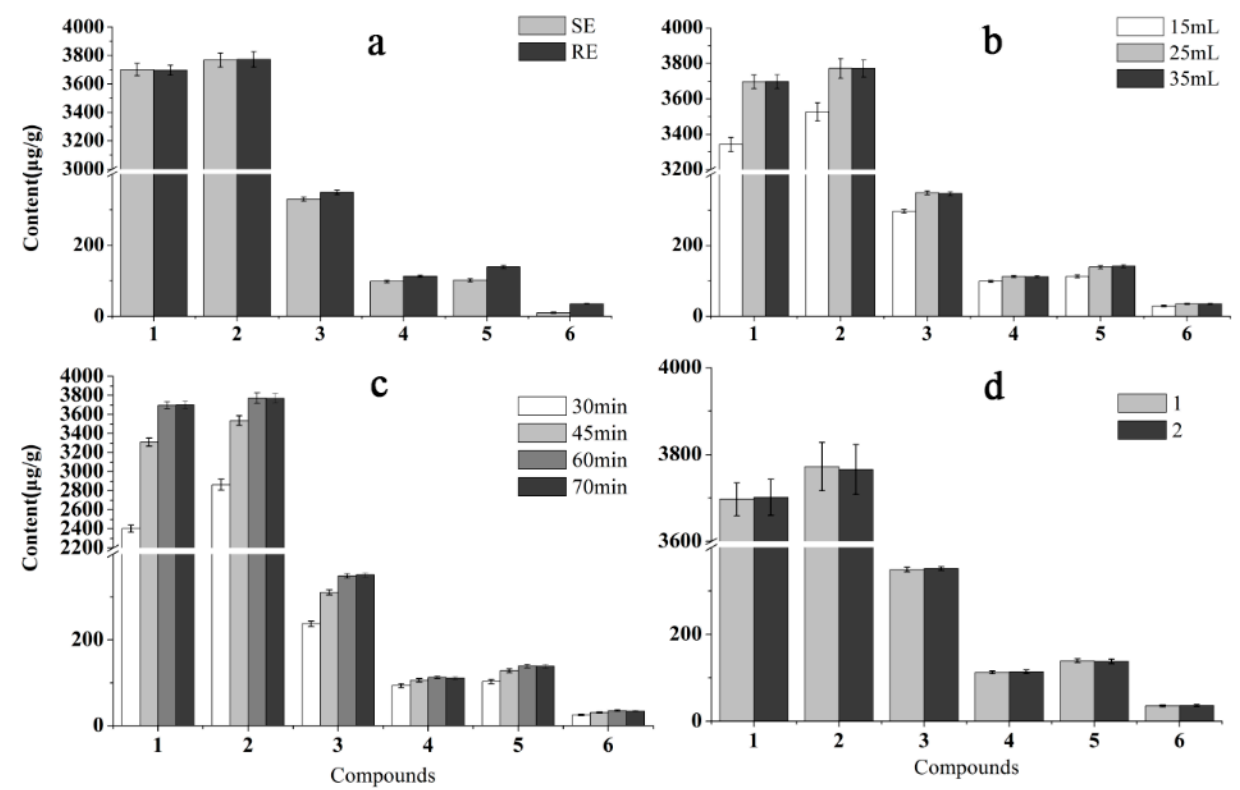

Figure 3. Effects of (a) method (SE, sonication extraction; RE, refluxing extraction); (b) solvent volume; (c) extraction time; and (d) extraction repetition on the extraction efficiency of target analytes in S13 M. officinalis sample from Hainan province. 


\subsection{Method Validation}

Method validation was performed by evaluating the linearity, limit of detection (LOD), limit of quantification (LOQ), precision, repeatability, stability, and recovery. All results are listed in Table 2. The calibration curves of six target compounds exhibited relatively wide concentration ranges, with correlation coefficients higher than 0.9930. For all ingredients, the LODs ranged from 0.87 to $9.19 \mathrm{ng} / \mathrm{mL}$, and the LOQs from 2.60 to $27.57 \mathrm{ng} / \mathrm{mL}$. The inter- and inter-day precisions of the investigated components exhibited an RSD of less than $2.80 \%$ and $4.21 \%$, respectively. The average recoveries of these compounds were in the range of $95.32-99.86 \%$ with RSD values between $1.75 \%$ and $4.23 \%$ (Table 3), indicating good reliability and accuracy of the proposed method. In addition, all analytes exhibited good stability and repeatability, with RSDs for the peak area of less than $5.0 \%$.

Table 2. Calibration curves, test range, limit of detection (LOD), limit of quantification (LOQ), precision, and repeatability for the six analytes.

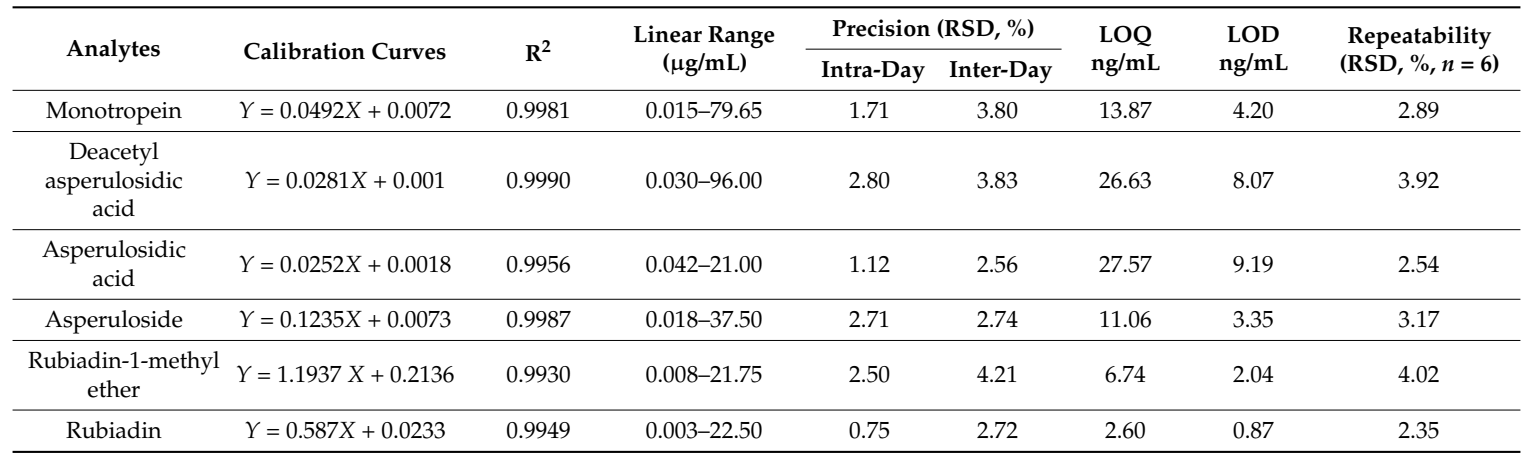

Table 3. Recoveries of the six compounds.

\begin{tabular}{|c|c|c|c|c|c|}
\hline Analytes & Sample (g) & Origin $(\mu \mathrm{g})$ & Spiked $(\mu \mathrm{g})$ & Found $(\mu \mathrm{g})$ & Mean Recovery (\%) (RSD, \%) \\
\hline \multirow{3}{*}{ Monotropein } & \multirow{3}{*}{0.5} & \multirow{3}{*}{1848.45} & 1480 & 3304.33 & $98.37(3.23)$ \\
\hline & & & 1850 & 3680.69 & $99.04(2.15)$ \\
\hline & & & 2220 & 4059.13 & $99.58(3.06)$ \\
\hline \multirow{3}{*}{ Deacetyl asperulosidic acid } & \multirow{3}{*}{0.5} & \multirow{3}{*}{1883.74} & 1500 & 3351.19 & $97.83(4.07)$ \\
\hline & & & 1880 & 3731.03 & $98.26(2.38)$ \\
\hline & & & 2260 & 4113.01 & $98.64(1.95)$ \\
\hline \multirow{3}{*}{ Asperulosidic acid } & \multirow{3}{*}{0.5} & \multirow{3}{*}{174.43} & 140 & 310.70 & $97.33(2.84)$ \\
\hline & & & 175 & 346.00 & $98.04(3.37)$ \\
\hline & & & 210 & 384.14 & $99.86(3.69)$ \\
\hline \multirow{3}{*}{ Asperuloside } & \multirow{3}{*}{0.5} & \multirow{3}{*}{56.32} & 45 & 100.61 & $98.41(4.23)$ \\
\hline & & & 55 & 110.13 & $97.83(3.94)$ \\
\hline & & & 67.5 & 122.63 & $98.23(2.78)$ \\
\hline \multirow{3}{*}{ Rubiadin-1-methyl ether } & \multirow{3}{*}{0.5} & \multirow{3}{*}{69.53} & 55 & 122.58 & $96.47(2.94)$ \\
\hline & & & 70 & 136.56 & 95.77 (2.62) \\
\hline & & & 84 & 149.59 & $95.32(3.15)$ \\
\hline \multirow{3}{*}{ Rubiadin } & \multirow{3}{*}{0.5} & \multirow{3}{*}{17.62} & 14 & 31.27 & $97.48(1.75)$ \\
\hline & & & 17.5 & 34.63 & $97.17(2.77)$ \\
\hline & & & 21 & 37.88 & $96.48(3.28)$ \\
\hline
\end{tabular}

\subsection{Sample Analysis}

The validated UPLC-QqQ-MS/MS method was applied to simultaneously quantify the six compounds in 17 batches of $M$. officinalis samples collected from different regions in China. In LC-MS, especially in liquid chromatography coupled to electrospray mass spectrometry, the ion suppression/enhancement effects from matrix can significantly reduce or enhance the analyte response. Appropriate internal standard (IS) can overcome ion suppression/enhancement effects. Therefore, IS was used to minimize variation between samples. The target components were identified based on comparison of retention time, precursor, and product ions obtained from MS/MS analysis of the 
standard compounds. Representative chromatograms of MRM scans of the standards and sample (S13) are shown in Figure 2. Quantitative analysis results are summarized in Table 4. These results indicated that there were significant differences in the contents of monotropein, deacetyl asperulosidic acid, asperulosidic acid, asperuloside, rubiadin-1-methyl ether, and rubiadin among the 17 samples. Monotropein and deacetyl asperulosidic acid were found to be the most abundant in all samples, varying from 1016.25 to $3696.90 \mu \mathrm{g} / \mathrm{g}$ ( $\mu \mathrm{g}$ per g of dry weight) and from 817.64 to $3767.48 \mu \mathrm{g} / \mathrm{g}$, respectively. Similar results have also been reported previously [16]. Asperulosidic acid and asperuloside were relatively abundant and their contents were in the ranges of 33.05-348.87 $\mu \mathrm{g} / \mathrm{g}$ and 1.13-112.64 $\mu \mathrm{g} / \mathrm{g}$, respectively. However, the two compounds were not detected in three samples (S3, S5, and S17). Rubiadin-1-methyl ether and rubiadin were detected in all samples but in variable amounts.

Table 4. Quantitative analytical results of M. officinalis $(\mu \mathrm{g} / \mathrm{g}, n=3)$.

\begin{tabular}{cccccccc}
\hline No. & Origins & $\mathbf{1}$ & $\mathbf{2}$ & $\mathbf{3}$ & $\mathbf{4}$ & $\mathbf{5}$ & $\mathbf{6}$ \\
\hline S1 & Guangdong & 2497.58 & 2766.00 & 246.94 & 33.95 & 113.49 & 11.15 \\
S2 & Guangdong & 2125.89 & 2179.01 & 171.42 & 8.44 & 184.22 & 21.64 \\
S3 & Guangdong & 1861.98 & 1771.73 & 83.22 & ND & 116.76 & 7.95 \\
S4 & Guangdong & 2141.90 & 2162.22 & 175.05 & 5.98 & 107.61 & 15.67 \\
S5 & Guangdong & 1016.25 & 817.64 & ND & ND & 42.93 & 3.80 \\
S6 & Guangdong & 1590.15 & 1510.59 & 93.76 & 7.38 & 57.04 & 19.31 \\
S7 & Guangdong & 1540.68 & 1593.63 & 46.14 & 1.09 & 146.63 & 17.58 \\
S8 & Guangdong & 1513.27 & 1458.78 & 67.97 & 6.04 & 143.97 & 208.70 \\
S9 & Guangdong & 1827.98 & 1695.86 & 86.50 & 3.08 & 87.69 & 12.79 \\
S10 & Hainan & 2310.95 & 1990.72 & 91.30 & 15.19 & 81.43 & 28.17 \\
S11 & Hainan & 1907.49 & 1697.96 & 151.21 & 15.03 & 118.81 & 38.88 \\
S12 & Hainan & 3020.44 & 3308.44 & 234.72 & 19.95 & 65.85 & 7.01 \\
S13 & Hainan & 3696.90 & 3767.48 & 348.87 & 112.64 & 139.05 & 35.25 \\
S14 & Guangxi & 2046.66 & 1838.41 & 50.22 & 1.13 & 116.43 & 10.84 \\
S15 & Guangxi & 1521.74 & 1784.73 & 116.21 & 11.25 & 167.85 & 24.15 \\
S16 & Fujian & 1940.38 & 1805.78 & 33.05 & 2.07 & 172.22 & 20.89 \\
S17 & Fujian & 1266.58 & 1199.37 & ND & ND & 123.04 & 11.40 \\
\hline
\end{tabular}

In China, M. officinalis is mainly distributed in Southern China. Hainan island $\left(18^{\circ} 10^{\prime}-20^{\circ} 10^{\prime} \mathrm{N}\right.$ latitude and $108^{\circ} 37^{\prime}-111^{\circ} 03^{\prime}$ E longitude) is the only tropical zone of China, and the climate is different from other regions. The content of some compounds (anthraquinones) in Hainan samples being higher than samples from other regions may correlate with the climate. Similar finding has been reported [23]. However, Shi et al. found that the content of five anthraquinones (1-methoxy-2-hydroxy anthraquinone, 1,2-dimethoxy-3-hydroxy anthraquinone, rubiadin-1-methylether, 1,3-dihydroxy-2-methoxy anthraquinone, rubiadin) in Guangxi samples were highest in all samples (except Hainan) [14]. Furthermore, harvest time is also another major factor affecting the content of monotropein in M. officinalis [24]. In fact, there is no successful report on relationship between content of compounds in $M$. officinalis and environmental factors, geography, or harvesting time. Fortunately, the proposed UPLC-MS/MS method is suitable for determination of the target analytes in M. officinalis.

\subsection{UPLC-Q/TOF-MS Identification}

To date, more than 30 anthraquinones and 7 iridoids have been isolated as the main effective components in the root of $M$. officinalis. These components share the same basic skeleton structure with different substituting groups. Among these compounds, there are seven pairs of isomers in anthraquinones and one pair of isomer (monotropein and deacetyl asperulosidic acid) in iridoid glycosides. Negative ESI ionization mode was found to be more sensitive than the positive ionization mode for detecting iridoid glycosides and anthraquinones $[25,26]$. Therefore, the target compositions 
were identified by UPLC-ESI-Q/TOF-MS in negative ionization mode. In the negative ESI experiments, the deprotonated molecule $[\mathrm{M}-\mathrm{H}]^{-}$was detected in the MS/MS spectra of all the target analytes within $5.0 \mathrm{ppm}$ (Table 5). In addition, comparison of the retention time and MS/MS spectra information was achieved by using the reference compounds. Due to similar structures of the target components-for example, between deacetyl asperulosidic acid and monotropein - the fragmentation pathways of iridoid glycosides and anthraquinones in M. officinalis were examined.

The MS/MS spectra and fragmentation pathway of deacetyl asperulosidic acid is shown in Figure 4 . The main and typical losses of this compound are $\mathrm{H}_{2} \mathrm{O}(18 \mathrm{Da}), \mathrm{CO}_{2}(44 \mathrm{Da})$, and glucose (Glc) unit (162 Da). Furthermore, deacetyl asperulosidic acid formed a product ion at $m / z 208.96$, due to the loss of glucoside $(180 \mathrm{Da})$ from the deprotonated molecule $[\mathrm{M}-\mathrm{H}]^{-}$or the loss of one molecule of $\mathrm{H}_{2} \mathrm{O}$ from $m / z 226.97$ [M $\left.-\mathrm{H}-\mathrm{Glc}\right]^{-}$. The product ions at $\mathrm{m} / z 164.98$ and $\mathrm{m} / z 190.96$ were attributed to the loss of one molecule $\mathrm{CO}_{2}$ and $\mathrm{H}_{2} \mathrm{O}$ from $m / z$ 226.97. This is also supported by previous findings of deacetyl asperulosidic acid in this plant and in Hedyotis diffusa [27,28].

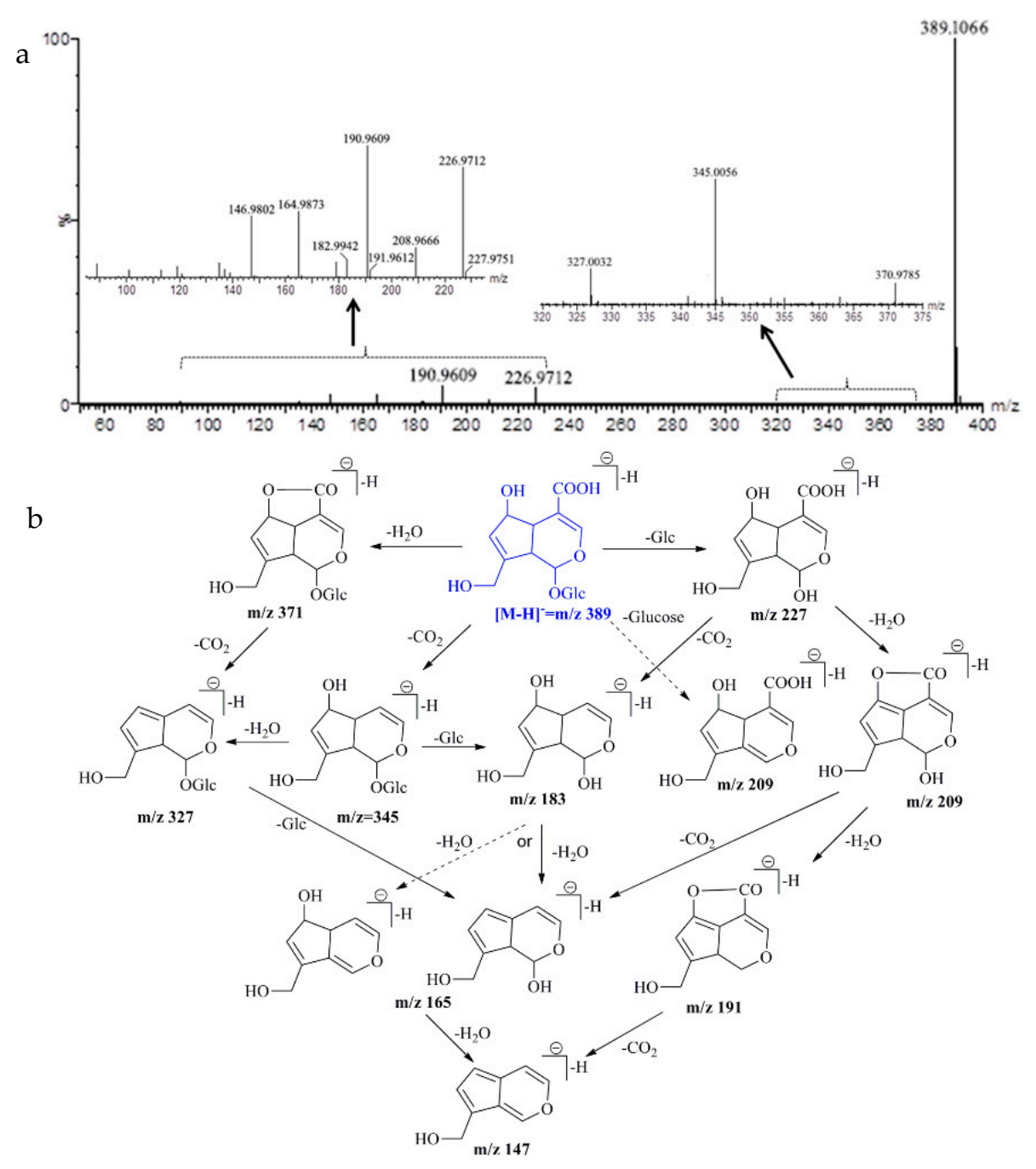

Figure 4. MS/MS spectra (a) and the proposed fragmentation pathway (b) of deacetyl asperulosidic acid.

For rubiadin, the product ions at $\mathrm{m} / \mathrm{z} 225.01$ and $\mathrm{m} / \mathrm{z} 197.01$ were formed by the neutral losses of two $-\mathrm{CO}(28 \mathrm{Da})$ of the deprotonated molecule $[\mathrm{M}-\mathrm{H}]^{-}$at $\mathrm{m} / z$ 253.00. The fragment ion at $m / z$ 209.01 was formed by the elimination of $44 \mathrm{Da}$ of $[\mathrm{M}-\mathrm{H}]^{-} \mathrm{m} / z 253.00$, which corresponded to the loss of one molecule of $\mathrm{CO}_{2}$. In addition, the fragment ions $m / z 181.02$ and $m / z 195.00$ were occurred 
by the loss of $\mathrm{CO}(28 \mathrm{Da})$ and $\mathrm{CH}_{2}(14 \mathrm{Da})$ from product ion at $\mathrm{m} / z$ 209.01, respectively. The proposed fragmentation pathway of rubiadin (Figure 5) was in accordance with the previous reports [29,30].

Table 5. Mass data of the six analytes from M. officinalis by UPLC-Q/TOF-MS.

\begin{tabular}{|c|c|c|c|c|c|}
\hline Analyte & $\begin{array}{l}\text { Molecular } \\
\text { Formula }\end{array}$ & $\begin{array}{l}\text { Theoretical Mass } \\
\text { (Da) }\end{array}$ & $\begin{array}{l}\text { Measured Mass } \\
\text { (Da) }\end{array}$ & Error (ppm) & $\begin{array}{l}\text { Fragment Ions } \\
\left(\mathrm{ESI}^{-}, m / z\right)\end{array}$ \\
\hline Monotropein & $\mathrm{C}_{6} \mathrm{H}_{22} \mathrm{O}_{11}$ & $389.1084[\mathrm{M}-\mathrm{H}]^{-}$ & $389.1066[\mathrm{M}-\mathrm{H}]^{-}$ & -4.62 & $\begin{array}{l}226.9712,190.9609, \\
164.9873,146.9802\end{array}$ \\
\hline $\begin{array}{l}\text { Deacetyl asperulosidic } \\
\text { acid }\end{array}$ & $\mathrm{C}_{16} \mathrm{H}_{22} \mathrm{O}_{11}$ & $389.1084[\mathrm{M}-\mathrm{H}]^{-}$ & $389.1072[\mathrm{M}-\mathrm{H}]^{-}$ & -3.08 & $\begin{array}{l}146.9305,165.0189, \\
227.0082,190.9921\end{array}$ \\
\hline Asperulosidic acid & $\mathrm{C}_{18} \mathrm{H}_{24} \mathrm{O}_{12}$ & $431.1190[\mathrm{M}-\mathrm{H}]^{-}$ & $431.1184[\mathrm{M}-\mathrm{H}]^{-}$ & -1.39 & $\begin{array}{l}146.9305,165.0189, \\
251.0062,119.0033\end{array}$ \\
\hline Asperuloside & $\mathrm{C}_{18} \mathrm{H}_{22} \mathrm{O}_{11}$ & $413.1084[\mathrm{M}-\mathrm{H}]^{-}$ & $413.1092[\mathrm{M}-\mathrm{H}]^{-}$ & 1.94 & $\begin{array}{l}146.9926,190.9722, \\
233.0963,369.1387\end{array}$ \\
\hline Rubiadin-1-methyl ether & $\mathrm{C}_{16} \mathrm{H}_{12} \mathrm{O}_{4}$ & $267.0657[\mathrm{M}-\mathrm{H}]^{-}$ & $267.0653[\mathrm{M}-\mathrm{H}]^{-}$ & 1.50 & $224.0036,252.9935$ \\
\hline Rubiadin & $\mathrm{C}_{15} \mathrm{H}_{10} \mathrm{O}_{4}$ & $253.0501[\mathrm{M}-\mathrm{H}]^{-}$ & $253.0503[\mathrm{M}-\mathrm{H}]^{-}$ & 0.79 & $\begin{array}{c}225.0101,209.0170, \\
181.0270\end{array}$ \\
\hline
\end{tabular}

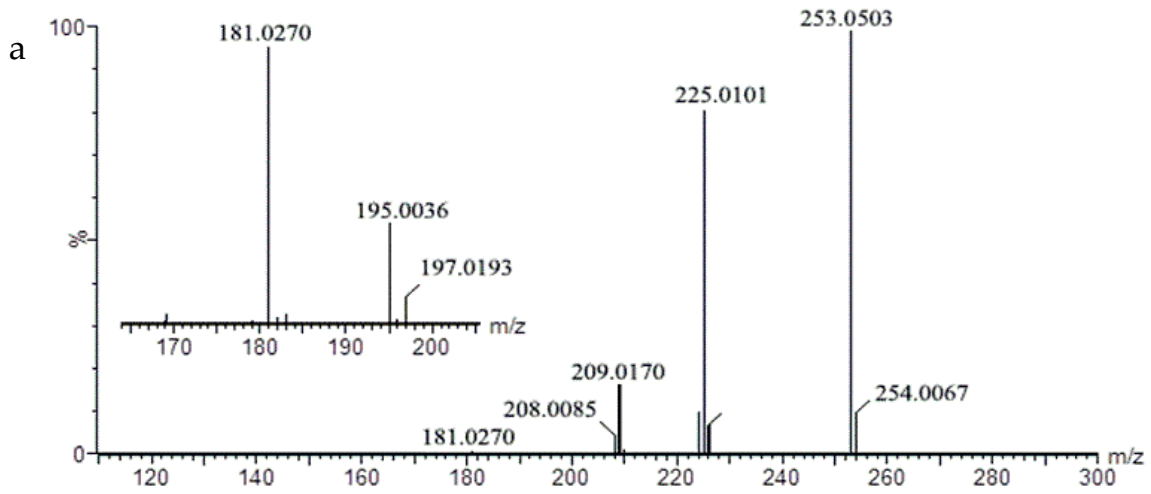

b

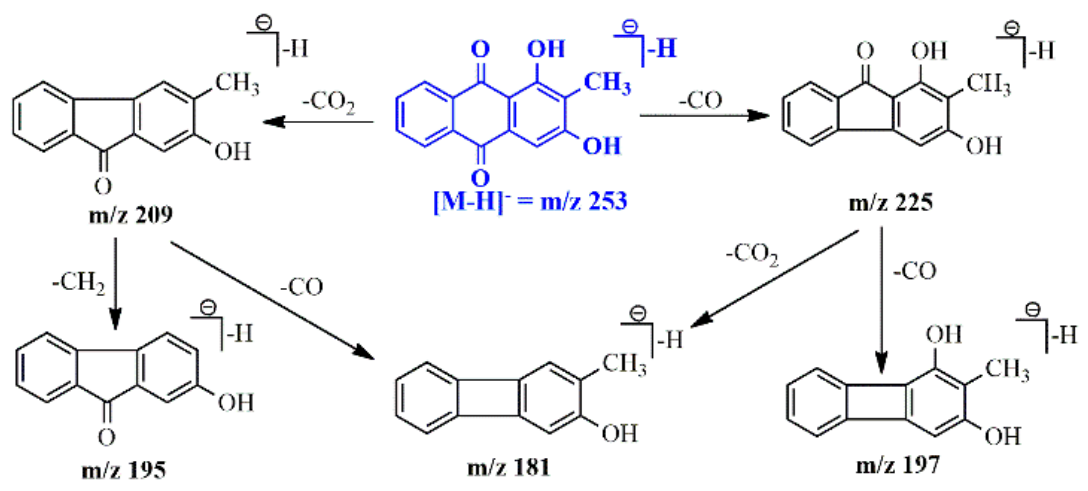

Figure 5. MS/MS spectra (a) and the proposed fragmentation pathway (b) of rubiadin.

\section{Materials and Methods}

\subsection{Chemicals, Reagents, and Samples}

HPLC-grade acetonitrile, methanol, and formic acid were purchased from Thermo Fisher Scientific (Fisher, Fair Lawn, NJ, USA). Analytical grade methanol and ethyl acetate were supplied by the Beijing Chemical Works (Beijing, China). Water used in the experiment was generated by a Milli-Q water purification system (Millipore, Milford, MA, USA). Reference standards of monotropein, deacetyl asperulosidic acid, asperulosidic acid, and asperuloside were purchased from Shanghai Tauto Bio-Technology Co., LTD. (Shanghai, China). Rubiadin-1-methyl ether, rubiadin, and jaceosidin (internal standard, IS) were obtained from Chengdu Chroma-Biotechnology Co., Ltd. (Chengdu, China). The purities of all standards were above $98.0 \%$. The chemical structures of these reference standards are shown in Figure 1. 
The roots (17 batches) of Morinda officinalis were collected in December of 2016 from Guangdong, Hainan, Guangxi, and Fujian provinces of China. The samples were identified by Prof. Meihua Yang (Institute of Medicinal Plant Development, Chinese Academy of Medical Sciences \& Peking Union Medical College, Beijing, China).

\subsection{UPLC-QqQ-MS/MS}

Chromatographic separation was performed on a UPLC system (Acquity H-Class, Corp., Milford, MA, USA) containing a binary solvent manager, a column manager, and a sample manager. The samples were analyzed on an Xbridge BEH C18 column $(150 \mathrm{~mm} \times 4.6 \mathrm{~mm}, 5 \mu \mathrm{m}$; Waters Corp., Milford, MA, USA) and the column temperature was set at $40{ }^{\circ} \mathrm{C}$. The mobile phase consisted of acetonitrile (A) and $0.3 \%$ formic acid aqueous solution (B) to enable a gradient elution following the steps: $0 \mathrm{~min}, 7 \% \mathrm{~A} ; 5 \mathrm{~min}, 10 \% \mathrm{~A} ; 8 \mathrm{~min}, 45 \% \mathrm{~A} ; 13 \mathrm{~min}, 60 \% \mathrm{~A} ; 22 \mathrm{~min}, 90 \% ; 25 \mathrm{~min} 90 \% \mathrm{~A}$; $30 \mathrm{~min}, 7 \% \mathrm{~A}$; finally, the mobile phase was returned to, and remained in, the initial condition for $5 \mathrm{~min}$ to re-equilibrate the system before the next injection. The flow rate was $0.4 \mathrm{~mL} / \mathrm{min}$ and the injection volume was $5 \mu \mathrm{L}$. The UPLC system was equipped with a Waters triple quadrupole mass spectrometer (Xevo TQ-D, Waters Corp., Milford, MA, USA) with an electrospray ionization (ESI) source. Analytes were detected and quantified by MRM in negative ionization mode with argon as collision gas. The capillary voltage was set at $2.5 \mathrm{kV}$. Nitrogen was used as desolvation gas at a flow rate of $650 \mathrm{~L} / \mathrm{h}$ at a temperature of $350{ }^{\circ} \mathrm{C}$. The flow rate of the cone gas was $150 \mathrm{~L} / \mathrm{h}$ and the source temperature was $150^{\circ} \mathrm{C}$. Cone voltage and collision energy were individually optimized by direct infusion of analytes and IS into the MS system. MS/MS parameters of the six investigated compounds and IS are listed in Table 1. For LC-MS/MS analysis, data acquisition and handling and instrument control were performed using MassLynx software (Waters Corp., Milford, MA, USA).

\subsection{UPLC-Q/TOF-MS/MS}

The above-described UPLC conditions were used for UPLC-QqQ-MS/MS. A quadrupole time-of-flight mass spectrometer (Xevo G2-XS, Waters Corp., Manchester, UK) equipped with an ESI source was coupled to the UPLC system. Detection was implemented in the MSE centroid mode over a mass range of 500-1200 Da with a scan rate of 10 per second. The analyzer sensitivity mode was used. Leukine encephalin was infused as lockspray via a reference probe for in-run mass correction. Capillary voltage was set at $2.5 \mathrm{kV}$ for ESI. Desolvation gas (nitrogen) was delivered at $600 \mathrm{~L} / \mathrm{h}$ and $400{ }^{\circ} \mathrm{C}$. Flow rate of cone gas was set to $50 \mathrm{~L} / \mathrm{h}$ and source temperature was set to $125^{\circ} \mathrm{C}$. Collision energy was ramped in the high energy function from 30 to $50 \mathrm{eV}$ using argon as collision gas. MassLynx software (Waters Corp.) was used for post-acquisition analysis.

\subsection{Sample Preparation}

An aliquot of $1.0 \mathrm{~g}$ of $M$. officinalis was extracted by refluxing with $25 \mathrm{~mL}$ of methanol for $1 \mathrm{~h}$. The extracted solution was cooled to room temperature and made up to the original weight with methanol. The obtained solution was filtered and subsequently centrifuged for $15 \mathrm{~min}$ at 12,000 rpm. Then, $0.5 \mathrm{~mL}$ of IS $(1.6 \mu \mathrm{g} / \mathrm{mL})$ was add to $0.5 \mathrm{~mL}$ of the supernatant fluid and the mixture was vortexed for $30 \mathrm{~s}$. A $5 \mu \mathrm{L}$ aliquot was introduced into the UPLC-MS/MS system for analysis. All samples were determined in triplicate.

\subsection{Standard Solution Preparation}

Appropriate amounts of monotropein, deacetyl asperulosidic acid, asperulosidic acid, asperuloside, rubiadin-1-methyl ether, and rubiadin were separately weighed and dissolved in methanol to get the stock solutions. Then, the six stock solutions were mixed and diluted with methanol to prepare a final mixed standard solution containing $159.3 \mu \mathrm{g} / \mathrm{mL}$ of monotropein, $192 \mu \mathrm{g} / \mathrm{mL}$ of deacetylasperulosidic acid, $42 \mu \mathrm{g} / \mathrm{mL}$ of asperulosidic acid, $75 \mu \mathrm{g} / \mathrm{mL}$ of asperuloside, $43.5 \mu \mathrm{g} / \mathrm{mL}$ of rubiadin-1-methyl ether, and $45 \mu \mathrm{g} / \mathrm{mL}$ of rubiadin, respectively. A series of working solutions of 
these ingredients were obtained by diluting mixed standard solution with methanol at the appropriate concentrations. A specific quantity of jaceosidin was dissolved in methanol to produce the IS solution with a concentration of $0.8 \mu \mathrm{g} / \mathrm{mL}$. All the solutions were stored at $4{ }^{\circ} \mathrm{C}$ before use.

\subsection{Method Validation}

\subsubsection{Linearity and Limit of Quantification}

The calibration curves of nine concentration levels of each standard were constructed by plotting the peak area ratio of the analyte to IS versus their concentration. Limits of detection (LODs) and quantification (LOQs) were determined at a signal-to-noise ratio $(\mathrm{S} / \mathrm{N})$ of about 3 and 10 , respectively.

\subsubsection{Precision, Repeatability, and Stability}

Precision was determined by replicated analyses $(n=5)$ of standard samples within one day (intra-day variation) and on three consecutive days (inter-day variation). Then, the RSD value of the peak area for each analyte was computed. To confirm repeatability, six different sample solutions prepared from the same sample were analyzed, and variations were expressed by RSD. For stability investigation, one of the sample solutions (S13) was stored at room temperature (about $25^{\circ} \mathrm{C}$ ) and analyzed at $0,2,4,8,16$, and $24 \mathrm{~h}$, respectively.

\subsubsection{Recovery}

Recovery test was carried out for the accuracy of the established method. The test was carried out by adding known amount of the six standards at low ( $80 \%$ of the known amount), medium (the same as the known amount), and high ( $120 \%$ of the known amount) levels. The spiked samples were then extracted, processed, and quantified according to the abovementioned methods. The average recovery was calculated by the following formula: recovery $(\%)=($ found amount - original amount $) /$ spiked amount $\times 100$.

\section{Conclusions}

For the first time, a rapid, sensitive, and convenient UPLC-ESI-QqQ-MS/MS method was developed and validated for the simultaneous determination of four iridoid glycosides (monotropein, deacetyl asperulosidic acid, asperulosidic acid, and asperuloside) and two anthraquinones (rubiadin-1-methyl ether and rubiadin) in M. officinalis. The developed method offers the advantages of high sensitivity and simple sample preparation. It was successfully applied to simultaneously quantify the six bioactive components in 17 batches of $M$. officinalis samples collected from different regions of China. Results have shown that monotropein and deacetyl asperulosidic acid were the abundant constituents in M. officinalis. The two main iridoid glycosides were chosen as the marker compounds for the quality assessment of $M$. officinalis. In addition, the proposed fragmentation behaviors of the analytes may provide a reference for screening iridoid glycosides and anthraquinones in $M$. officinalis due to similarity in their skeleton and fragment groups.

Author Contributions: J.W. and M.Y. conceived and designed the experiments; X.Z. performed the experiments and wrote the paper. All authors have read, revised and approved the final manuscript.

Acknowledgments: This work was supported by the key Research Project of Hainan Province, China (Grant No. ZDYF2016174), National Natural Science Foundation of China (No. 81603398) and CAMS Innovation Fund for Medical Sciences (CIFMS) (Grant No. 2017-I2M-1-013).

Conflicts of Interest: The authors declare no conflict of interest. 


\section{References}

1. Yong, J.P.; Lu, C.Z.; Huang, S.J.; Wu, X.Y. Chemical components isolated from the roots of Morinda officinalis. Chem. Nat. Compd. 2015, 51, 548-549. [CrossRef]

2. Chen, D.L.; Li, N.; Lin, N.; Long, H.M.; Li, H.; Chen, J.; Zhang, H.M.; Zeng, C.C.; Liu, S.H. Confocal mirco-raman spectroscopic analysis of the antioxidant protection mechanism of the oligosaccharides extracted from Morinda officinalis on human sperm DNA. J. Ethnopharmacol. 2014, 153, 119-124. [CrossRef] [PubMed]

3. Chinese Pharmacopoeia Commission. Pharmacopoeia of People's Republic of China; Chemical Industry Press: Beijing, China, 2015.

4. Wu, Y.B.; Zheng, C.J.; Qin, L.P.; Sun, L.N.; Han, T.; Jiao, L.; Zhang, Q.Y.; Zhong, J.Z. Antiosteoporotic activity of anthraquinones from Morinda officinalis on osteoblasts and osteoclasts. Molecules 2009, 14, 573-583. [CrossRef] [PubMed]

5. Zhang, H.L.; Li, J.; Li, G.; Wang, D.M.; Zhu, L.P.; Yang, D.P. Structural characterization and anti-fatigue activity polysaccharides from the roots of Morinda officinalis. Int. J. Biol. Macromol. 2009, 44, 257-261. [CrossRef] [PubMed]

6. Soon, Y.Y.; Tan, B.K.H. Evaluation of the hypoglycemic and antioxidant activities of Morinda officinalis in streptozotocin-Induced diabetic rats. Singap. Med. J. 2002, 43, 77-85.

7. Zhang, Z.Q.; Yuan, L.; Yang, M.; Luo, Z.P.; Zhao, Y.M. The effect of Morinda officinalis How, a Chinese traditional medicinal plant, on the DRL 72-s schedule in rats and the forced swimming test in mice. Pharmacol. Biochem. Behav. 2002, 72, 39-43. [CrossRef]

8. Choi, J.; Lee, K.; Choi, M.; Nam, J.H.; Jung, H.J.; Park, S.K.; Park, H.J. Antinociceptive anti-inflammatory effect of monotropein isolated from the root of Morinda officinalis. Biol. Pharm. Bull. 2005, 28, 1915-1918. [CrossRef] [PubMed]

9. Li, C.M.; Dong, J.; Tian, J.C.; Deng, Z.P.; Song, X.J. LC/MS/MS determination and pharmacokinetic study of iridoid glycosides monotropein and deacetylasperulosidic acid isomers in rat plasma after oral administration of Morinda officinalis extract. Biomed. Chromatogr. 2016, 30, 163-168. [CrossRef] [PubMed]

10. Li, P.; Qi, L.W.; Liu, E.H.; Zhou, J.L.; Wen, X.D. Analysis of Chinese herbal medicines with holistic approaches and integrated evaluation models. Trac-Trend Anal. Chem. 2008, 27, 66-77. [CrossRef]

11. Bao, L.; Qin, L.; Liu, L.; Wu, Y.; Han, T.; Xue, L.; Zhang, Q. Anthraquinone compounds from Morinda officinalis inhibit osteoclastic bone resorption in vitro. Chem.-Biol. Interact. 2011, 194, 97-105. [CrossRef] [PubMed]

12. Zhang, Z.G.; Zhang, Q.Y.; Yang, H.; Liu, W.; Zhang, N.D.; Qiu, L.P.; Xin, H.L. Monotropein isolated from the roots of Morinda officinalis increases osteoblastic bone formation and prevents bone loss in ovariectomized mice. Fitoterapia 2016, 110, 166-172. [CrossRef] [PubMed]

13. Kyoung, K.; Byungkil, C.; Mi, C.; Yeong, L.; Won, L. Separation and quantitative analysis of anthraquinones in Morinda officinalis How. by HPLC. Planta Med. 2006, 72, 1069. [CrossRef]

14. Shi, J.; Liu, Z.; Wang, L.; Ji, T.Z. Determination of five active components in Morinda officinalis from different habitats by HPLC. Chin. Med. Mat. 2015, 38, 245-248.

15. Wang, Y.L.; Cui, H.M.; Huang, S.J.; Li, Q.; Lei, H.M. Determination of main iridoid glycosides from Morindae officinalis Radix of different producting areas by HPLC. Chin. Med. Mat. 2011, 34, 1187-1190.

16. Yang, T.C.; Xu, J.; Liang, Y.; Liu, J.; Ding, P. Determination of momotropein from Radix Morindae officinalis by HPLC. West China J. Pharm. Sci. 2008, 23, 695-696.

17. Zhao, X.S.; Kong, W.J.; Zhou, Y.K.; Wei, J.H.; Yang, M.H. Evaluation and quantitative analysis of 11 compounds in Morinda officinalis using ultra-performance liquid chromatography-photodiode array coupled with chemometrics. J. Sep. Sci. 2017, 40, 3996-4003. [CrossRef] [PubMed]

18. Zhang, Y.; Guo, L.; Duan, L.; Dong, X.; Zhou, P.; Liu, E.H.; Li, P. Simultaneous determination of 16 phenolic constituents in Spatholobi caulis by high performance liquid chromatography/electrospray ionization triple quadrupole mass spectrometry. J. Pharm. Biomed. Anal. 2015, 102, 110-118. [CrossRef] [PubMed]

19. Kumar, S.; Chandra, P.; Bajpai, V.; Singh, A.; Srivastava, M.; Mishra, D.K.; Kumar, B. Rapid qualitative and quantitative analysis of bioactive compounds from Phyllanthus amarus using LC/MS/MS techniques. Ind. Crop Prod. 2015, 69, 143-152. [CrossRef] 
20. Wu, Y.H.; Jiang, X.L.; Zhang, S.X.; Dai, X.L.; Liu, Y.J.; Tan, H.R.; Gao, L.P.; Xia, T. Quantification of flavonol glycosides in Camellia sinensis by MRM mode of UPLC-QQQ-MS/MS. J. Chromatogr. B 2016, 1017-1018, 10-17. [CrossRef] [PubMed]

21. Li, Z.F.; Wang, Y.W.; Ouyang, H.; Lu, Y.; Qiu, Y.; Feng, Y.L.; Jiang, H.L.; Zhou, X.; Yang, S.L. A novel dereplication strategy for the identification of two new trace compounds in the extract of Gastrodia elata using UHPLC-Q/TOF-MS/MS. J. Chromatogr. B 2015, 988, 45-52. [CrossRef] [PubMed]

22. Liu, Q.F.; Jiao, Z.; Liu, Y.; Li, Z.D.; Shi, X.J.; Wang, W.J.; Wang, B.; Zhong, M.K. Chemical profiling of San-Huang decoction by UPLC-ESI-Q-TOF-MS. J. Pharm. Biomed. Anal. 2016, 131, 20-32. [CrossRef] [PubMed]

23. Chen, Z.; Deng, H.Z.; Mo, Q.L.; Lin, Z.W. Determination of the contents of valuable compositions of Morinda officinalis How in different regions and analysis of its protection for the liver. J. Hainan Norm. Univ. 2003, 16, 64-67.

24. Xu, J.Y.; Liang, Y.J.; Ding, P. Variations of monotropein in Morinda officinalis collected in different growth period. Chin. Tradit. Herb. Drugs 2007, 38, 772-774.

25. Li, C.M.; Zhang, X.L.; Xue, X.Y.; Zhang, F.Y.; Xu, Q.; Liang, X.M. Structural characterization of iridoid glycosides by ultra-performance liquid chromatography/electrospray ionization quadrupole time-of-flight tandem mass spectrometry. Rapid Commun. Mass Spectrom. 2008, 22, 1941-1954. [CrossRef] [PubMed]

26. Dong, J.; Wang, H.; Wan, L.R.; Hashi, Y.; Chen, S.Z. Identification and determination of major constituents in Polygonum cuspidatum Sieb. et Zucc by high performance liquid chromatography/electrospray ionization-ion trap/time-of-flight mass spectrometry. Chin. J. Chromatogr. 2009, 27, 425-430.

27. Wang, M.L.; Zhang, Q.Q.; Fu, S.; Liu, Y.H.; Liang, C.L.; Chen, N.; Ding, Y.S.; Wang, H.L.; Qu, X.M.; Zhao, B.S.; et al. Characterization of Morinda officinalis How. by UPLC-Q-TOF-MSE coupled with UNIFI database filiter. J. Chin. Mass Spectrom. Soc. 2017, 38, 75-82.

28. Li, C.M.; Xue, X.Y.; Zhou, D.Y.; Zhang, F.F.; Xu, Q.; Ren, L.L.; Liang, X.M. Analysis of iridoid glycosides in Hedyotis diffusa by high-performance liquid chromatography/electrospray ionization tandem mass spectrometry. J. Pharm. Biomed. Anal. 2008, 48, 205-211. [CrossRef] [PubMed]

29. Luo, Y.; Zhang, L.; Wang, W.H.; Liu, B. Components identification in Cassiae Semen by HPLC-IT-TOF-MS. J. Pharm. Anal. 2015, 35, 1408-1411.

30. Dong, H.J.; Chen, X.H.; Zeng, R. Rapid analysis on chemical constituents in roots of Rheum pumilum by UPLC coupled with hybrid quadrupole-orbit trap MS. Chin. Tradit. Herb. Drugs 2016, 47, 2428-2435.

Sample Availability: Samples of the compounds are not available from the authors.

(C) 2018 by the authors. Licensee MDPI, Basel, Switzerland. This article is an open access article distributed under the terms and conditions of the Creative Commons Attribution (CC BY) license (http:/ / creativecommons.org/licenses/by/4.0/). 